\title{
POLÍTICAS DE ESCALA E A CONFORMAÇÃO DE ESTRATÉGIAS-REDE DAS AÇÕES COLETIVAS NO ESPAÇO SISALEIRO DA BAHIA
}

\author{
Agripino Souza Coelho Neto* \\ Universidade do Estado da Bahia
}

\begin{abstract}
Resumo: 0 presente texto pretende analisar o papel das ações coletivas (associações, cooperativas e sindicatos de agricultores) no acionamento e na ativação das escalas geográficas para o desenvolvimento de suas atividades. O estudo foi realizado no Espaço Sisaleiro da Bahia (Brasil), onde um conjunto significativo de associações e cooperativas de agricultores e sindicatos de trabalhadores rurais tem se organizado em torno das escalas espaciais para viabilizar sua ação político-institucional e econômico-produtiva. A ação desses coletivos organizados em rede tem permitido a conformação e o fortalecimento de novas escalas de ação política, como no caso da criação do conselho territorial para viabilização da implantação de políticas de governo. Cooperativas, associações e sindicatos se apoiam nas escalas para compor organizações em diferentes níveis escalares (escala local, escala regional, escala do estado federado e escala nacional), buscando fortalecer seus propósitos e ampliar seu poder de barganha e influência. Analisando o comportamento espacial dessas variadas modalidades de ações coletivas, é possível considerar que elas desenvolvem políticas de escala, ou seja, a escala passa a significar muito mais que uma categoria de análise, mas se torna uma categoria da prática social e política. Nesse sentido, parte-se do pressuposto de que os grupos humanos produzem e tornam efetivas suas próprias escalas visando a alcançar suas metas e organizar seus comportamentos coletivos.
\end{abstract}

Palavras-chave: Escala. Rede. Cooperativismo. Associativismo. Sindicalismo. Espaço Sisaleiro da Bahia.

SCALE POLICIES AND THE DEVELOPMENT OF NETWORK STRATEGIES OF COLLECTIVE ACTIONS IN THE SISAL REGION OF BAHIA (BRAZIL) Abstract: This paper aims to analyze the role of collective initiatives of associations, cooperatives and farmers' unions in the mobilization and activation of geographical scales for the development of their activities. The study was conducted in the Sisal Region of Bahia (Brazil), where a significant number of farmers associations and cooperatives and rural workers' unions have been organizing their actions around spatial scales to enable their political-institutional and economic-productive influence. The gathering and action of these organized groups in a network have allowed the establishment and strengthening of new scales of political action, as seem in the case of the creation of a territorial council to facilitate the implementation of government policies. Cooperatives, associations, and unions rely on scales to form organizations at different scale levels (local, regional, federal and national scales), seeking to strengthen their performance and increase their bargaining power and influence. After analyzing the spatial behavior of these various forms of collective actions, it's reasonable to say that they develop scale policies, which means the scale becomes more than a category of analysis, but also a category of social and political practice. In this sense, it's assumed that human groups produce and utilize the scales in order to reach their goals and organize their own collective behaviors.

Keywords: Scale. Network. Cooperativism. Associativism. Syndicalism. Sisal Region of Bahia.

POLITIQUES D'ÉCHELLE ET FORMATION DES STRATÉGIES-RÉSEAU DES ACTIONS COLLECTIVES DANS LA RÉGION DU SISAL DE L'ÉTAT DE BAHIA Resumé: Cet article analyse le rôle des actions collectives (associations, coopératives et syndicats d'agriculteurs) dans la prise en compte et l'utilisation des échelles géographiques pour le développement de leurs activités. L'étude a été menée dans la région du sisal à Bahia (Brésil), où un ensemble important d'associations et de coopératives d'agriculteurs et de syndicats de travailleurs ruraux se sont organisés autour d'échelles spatiales pour que puisse être mise en place leur action politique et institutionnelle, économique et productive. L'action de ces groupements organisés en réseaux a permis la conformation et le renforcement de nouvelles échelles d'action politique, comme lors de la création du conseil territorial, pour permettre la mise en œuvre des politiques gouvernementales. Les coopératives, les associations et les syndicats prennent les échelles comme point de départ pour former des organisations à différents niveaux scalaires (échelle locale, échelle régionale, échelle fédérée et échelle nationale), dans le but de renforcer leurs objectifs et d'accroître leur pouvoir de négociation et d'influence. Si nous analysons le comportement spatial de ces diverses formes d'action collective il est possible de considérer qu'ils développent des politiques d'échelle, à savoir l'échelle vient signifier bien plus qu'une catégorie d'analyse, puisqu'elle devient une catégorie de la pratique sociale et politique. En ce sens, on suppose que les groupes humains produisent et rendent efficaces leurs propres échelles pour atteindre leurs objectifs et organiser leurs comportements collectifs.

Mots-clés: Échelle. Réseau. Coopérativisme. Associations. Syndicalisme. Région du sisal de l'État de Bahia. 
Introdução

O presente texto pretende analisar o papel das ações coletivas (associações, cooperativas e sindicatos) no acionamento e na ativação das escalas de governo para o desenvolvimento de suas atividades. 0 estudo foi realizado no Espaço Sisaleiro da Bahia (Brasil), onde um conjunto significativo de associações comunitárias rurais, cooperativas de agricultores e sindicatos de trabaIhadores rurais tem se organizado em torno das escalas de governo para viabilizar sua ação político-institucional e econômico-produtiva. A pesquisa utilizou como fonte documentos das organizações pesquisadas, a exemplo dos regimentos internos, relatórios de atividades, sites de notícias regionais e das organizações, e entrevistas semiestruturadas com lideranças das organizações sociais.

Adotamos como pressuposto que a ação desses coletivos organizados em rede tem permitido a conformação e o fortalecimento de novas escalas de ação política, como no caso da criação do conselho territorial para viabilização da implantação de políticas de governo. Cooperativas, associações e sindicatos se apoiam nas escalas de governo para compor organizações em diferentes níveis escalares (escala local, escala regional, escala do estado federado e escala nacional), buscando fortalecer seus propósitos e ampliar seu poder de barganha e influência.

O texto está organizado em quatro seções: (i) uma introdução; (ii) uma discussão conceitual sobre as políticas de escala; (iii) uma análise teórico-empírica sobre as manifestações das políticas de escala, observadas pelas ações de associações, cooperativas e sindicatos de agricultores camponeses; (iv) e por fim, as considerações finais.

\section{A escala como categoria de análise e como categoria da} prática socioespacial

A escala é uma categoria de análise apropriada por vários campos disciplinares, implicando significações e posturas metodológicas diversas, tendo se tornado, segundo Moore (2008), um conceito pesado, carregado de múltiplos, contraditórios e problemáticos significados. A despeito de sua discussão e emprego em outras disciplinas, não podem ser desconsiderados o acúmulo de reflexão e a teorização produzida na geografia, muito menos a posição de centralidade da escala no arsenal teórico deste campo disciplinar, sobretudo pela condição heurística que possui na investigação da dimensão espacial da realidade e dos processos sociais, econômicos, políticos e culturais que the são constitutivos.

Sem a intenção de recuperar a vasta discussão sobre escala (cujo lastro se encontra mais densamente situado na produção geográfica de origem anglo-saxônica), nos deteremos especialmente na discussão sistematizada por Moore (2008), estruturada em torno da distinção basilar entre escala como categoria de análise e escala como categoria da prática.

Moore (2008) reconhece dois difusos mas discerníveis raciocínios que nos parecem organizados em duas posições polarizadas, separando a (i) escala como entidade socioespacial material e a (ii) escala como construto epistemológico. No primeiro campo de significação o autor situou a concepção de escala de alguns geógrafos inspirados na tradição da economia política, conforme explicitado abaixo:

Neil Smith as descreve [as escalas] como a
"materialização da forças sociais em disputa"
(1993: 101)'e "plataformas para tipos específicos
de atividades sociais ... plataformas de espaço
absoluto em uma amplo mar do espaço relacional"
(2000: 725)2; Swyngedouw (1997a: 169) define
escala como a "materialização das relações sociais
de empoderamento e desempoderamento e a arena
através da qual elas operam". (MOORE, 2008, p. 204,
tradução nossa)

Segundo Moore (2008), para esses autores a escala não é uma categoria geográfica de análise independente, "[...] mas corresponde a processos materiais reais, eventos e formações espaciais" (MOORE, 2008, p. 204, tradução nossa). Assumindo uma direção contrária, o referido autor menciona algumas posições que concebem a escala exclusivamente como um construto epistemológico:

\begin{abstract}
Alternativamente, a escala tem sido caracterizada como um "tropo representacional" (JONES, 1998: 27) ${ }^{4}$ ou construção discursiva (KURTZ, 2003) ${ }^{5}$. A partir deste ponto de vista, a escala é fundamentalmente uma construção epistemológica que apresenta ordenações socioespaciais específicas. (MOORE, 2008, p. 204, tradução nossa)
\end{abstract}

Essa posição nos parece mais contudente na concepção de Castro (1995), que trata a escala como um problema epistemológico, considerando-a um artíficio analítico, uma estratégia de apreensão da realidade como representação:

(...) a escala é a escolha de uma forma de dividir o espaço, definindo-lhe uma realidade percebida/concebida, é uma forma de dar-Ihe figuração, uma representação, O texto mencionado é: SMITH, N. (1993) Homeless/global: scaling places. In: BIRD, J.; CURTIS, B.; PUTNAM, T.; ROBERTSON, G.; TICKNER, L. (eds.). Mapping the futures. London: Routledge, p. 87-119.

20 texto mencionado é: SMITH, N. (2000) Scale. In: JOHNSTON, R. J.; GREGORY D.; PRATT, G.; WATTS, M. (eds.). The dictionary of human geography. Malden-MA: Blackwell, p. 724-27.

${ }^{3} O$ texto mencionado é: SWYNGEDOUW, E. (1997) Excluding the other: the production of scale and scaled politics. In: LEE, R.; WILLS, J. (eds.). Geographies of economies. London: Arnold, p. 167-76.

${ }^{4}$ O texto mencionado é: JONES, K. (1998) Scale as epistemology. Political Geography, n. 17, p. $25-28$

${ }^{5} \mathrm{O}$ texto mencionado é: KURTZ, H. (2003) Scale frames and counter-scale frames: constructing the problem of environmental injustice. Political Geography, n. 22, p. 887-916. 
um ponto de vista que modifica a percepção mesma da natureza deste espaço, e, finalmente, um conjunto de representações coerentes e lógicas que substituem o espaço observado. (CASTRO, 1995, p. 136)

A crítica de Moore (2008) nos parece dirigida às concepções polarizadas e excludentes, que não consideram a possibilidade da distinção entre escala como categoria de análise e escala como categoria da prática, sendo as primeiras "categorias distantes da experiência, usadas pelos cientistas sociais", enquanto as segundas são "categorias da experiência cotidiana, desenvolvidas e empregadas pelos atores sociais ordinários", pois encontramos "muitos termos nas ciências sociais que operam como ambas as categorias", exercendo "mútua influência e recíproca ligação entre seus usos práticos e analíticos" (BOURDIEU, BRUBAKER e COOPER apud MOORE, 2008, p. 207, tradução nossa).

Para Brandão (2010), a distinção de Moore (2008) tem apenas um caráter didático, pois não se pode apartar a escala como categoria e unidade de análise, concebida como um recurso epistemológico e heurístico, da escala como categoria da prática, na condição de campo e instrumento das lutas sociais:

\begin{abstract}
A escala como uma categoria analítica e a escala como uma categoria da práxis política não estão apartadas. Selecionar analiticamente a escala mais conveniente dos problemas observados proporciona um melhor diagnóstico e possibilita sugerir coalizões de poder e decisões estratégicas acerca de como enfrentálos. 0 desafio (simultaneamente) científico e político consiste, portanto, em tratar de definir que e com que ferramentas cada escala pode revelar, mobilizar, desafiar, acionar, regular, comandar e controlar. (BRANDÃO, 2010, p. 246)
\end{abstract}

O entendimento de Brandão (2010) nos parece indicar a irredutível imbricação entre conhecimento científico e sua intervenção no mundo, reforçando o caráter político do conhecimento e sua capacidade não apenas de interpretar o mundo, mas de participar de sua produção, no sentido de produzir realidades sociais, inspirando e influenciando as práticas sociais. Nesse sentido, a tarefa consiste em "encontrar a escala adequada para definir um campo no qual as análises podem ser empreendidas, [mas, concomitantemente] onde se possam construir alianças e estratégias para resolver os problemas identificados" (BRANDÃO, 2010, p. 248).

Para além de uma posição dicotômica que antagoniza as duas categorias nos termos do embate filosófico entre idealismo e materialismo, concebemos a escala como uma categoria de análise desenvolvida e utilizada pela geografia (particularmente), sendo, portanto, um modo operatório "essencial para a compreensão do sentido e da visibilidade dos fenômenos numa perspectiva espacial" (CASTRO, 1995, p. 120).

No entanto, distanciando-nos daqueles que a con- cebem como pura abstração racionalista, consideramos que se trata de uma categoria teórica informada pela existência dinâmica do real, pelas manifestações sensíveis do empírico. Portanto, sua escolha como categoria de leitura da espacialidade das ações dos mais variados agentes sociais (que em nosso caso são as redes de organizações sociais) decorre das pistas que nos são fornecidas no processo de investigação. Mesmo quando produto da intuição, a escala como conceito teórico é alimentado pelos vestígios que a experiência nos proporciona/oferece.

Todavia, considerar a escala como uma categoria analítica não implica desconsiderar que os mais variados agentes sociais desenvolvem comportamentos espaciais, elaborando políticas, discursos e desenvolvendo práticas escalares, pois, "[...] os seres humanos produzem e fazem efetivas suas próprias escalas para alcançar suas metas e organizar seus comportamentos coletivos" (HARVEY, 2000, p. 108). Se considerarmos que as redes de organizações sociais do Espaço Sisaleiro da Bahia fazem uso da escala como estratégia para se organizar e alcançar seus propósitos, cujos entrelaçamentos de discursos e práticas têm o espaço como referência (ACSELRAD, 2002), é possível pensar que elas empreendem "políticas de escala". Para González (2010), as "políticas de escala" são definidas como:

\footnotetext{
(...) o campo no qual têm lugar as lutas materiais e discursivas entre diferentes atores para estabelecer configurações escalares hegemônicas. Nesta luta os atores utilizam "narrativas escalares" para justificar e dar impacto aos seus argumentos. (GONZÁLEZ, 2010, p. 125-126, tradução nossa)
}

González (2010) identifica e elenca quatro pilares constitutivos do enfoque das "políticas de escalas", oferecendo um conjunto de componentes que informam um conceito de escala: (i) as escalas não estão ontologicamente dadas como um a priori à espera de serem descobertas, mas são construções que expressam a organização dos processos sociais; (ii) a escala é "[...] tanto um objeto como um meio para as lutas econômico-políticas", pois, "[...] as relações escalares são, inevitavelmente, relações de poder", o que permite concluir que as escalas são expressões dessas relações (GONZÁLEZ, 2010, p. 126, tradução nossa); (iii) as escalas não podem ser concebidas como níveis organizados hierarquicamente, mas "[...] várias contribuições têm sugerido a metáfora da rede como a mais adequada para entender os processos nos quais opera a política de escalas" (GONZÁLEZ, 2010, p. 127, tradução nossa); (iv) as escalas devem ser entendidas como um conceito dinâmico e processual, pois equivalem a "[...] elaborações sociais conflitivas, são produções humanas coletivas, dinâmicas, multidimensionais, com os diversos atores e trajetórias históricas em disputa, em movimento processual, 
contingente e aberto" (BRANDÃO, 2010, p. 243, tradução nossa).

A concepção de escalas, como construções sociais conflitivas, processuais e dinâmicas que expressam relações de poder, nos sugere, inapelavelmente, dirigir nossa atenção para as ações dos sujeitos sociais, identificando seus interesses e aspirações, e buscando compreender suas ações, estratégias, políticas e discursos.

A contribuição dos geógrafos inspirados na tradição da Economia Política - geógrafos econômico-políticos para usar os termos de Moore (2008) - para o enfoque das políticas de escala nos parece seminal. No entanto, as críticas os acusam por seu foco estreito sobre as forças do capital e do Estado (MARSTON, 2000) 6 . Moore (2008) acusa um determinado negligenciamento das práticas escalares dos agentes sociais, que costumam ser deixadas à margem nas pesquisas geográficas. No entanto, ele identifica estudos e autores que têm focalizado o papel de ativistas da Aids, de partidos políticos, de ONGs ambientais e de organizações de bairro urbanas, ampliando nossa possibilidade de compreensão "[...] do elenco diversificado de participantes envolvidos na política de escala, e o extenso repertório de práticas escalares que empregam" (MOORE, 2008, p. 212, tradução nossa). Nessa direção nos parecem oportunos os questionamentos formulados por Dallabrida (2010):

(...) que atores, agentes e sujeitos? Quais são seus interesses específicos, seus instrumentos táticos e estratégicos? Em que escala espacial atuam? Em que escala se manifestam os fenômenos (local, metropolitana, nacional)? Onde se encontram os centros de decisão e comando determinantes dos atos territoriais sob análise? (p. 198)

A leitura da temporalidade das redes que se formaram e se consolidaram no Espaço Sisaleiro da Bahia indicou que as organizações sociais operam em múltiplas escalas geográficas. Essa constatação nos sugere a possibilidade de recorrer às diferentes escalas para compreender como os sujeitos se apropriam das escalas espaciais e constroem a pertinência de suas ações. No entanto, cada "nível escalar permite captar dimensões do real concreto, que de outra perspectiva não seriam assimilados, apreendendo algumas referências e enlaces que esta instância e corte analítico proporciona [...]" (BRANDÃO, 2010, p. 249-250).

Essa nos parece uma importante pista metodológica, uma vez que nosso fenômeno assume diferentes conteúdos e significados nas diferentes escalas. Os modos de organização e de operação das redes de coletivos organizados (associações, sindicatos e cooperativas de agricultores rurais) informam um comportamento espa-

${ }^{6} \mathrm{O}$ texto de Swyngedouw (2010) refletindo sobre a reconfiguração da escala tendo como referência o processo de globalização, centrado no embate entre as redes econômicas do capital e as escalas de regulação do Estado, é um exemplo ilustrativo dessa argumentação. cial com conteúdos particulares nas diferentes escalas geográficas. Em cada escala as redes constroem pertinências e são portadoras de significados específicos. Essa assertiva nos remete a alguns questionamentos fundamentais para nossa reflexão: como são acionadas e desenvolvidas as estratégias escalares das redes de organizações sociais? Quais os conteúdos assumidos pelas redes nas diferentes escalas geográficas? 0 que muda (em termos de sentido) nas diferentes escalas de operação das redes?

Multiescalaridade, políticas de escala e a conformação de estratégias-rede

\begin{abstract}
O movimento sindical é formado por cadeias, e também tem a corrente do movimento. O movimento sindical é isso, você começa da base para o município, para a região, é um trabalho integrado, uma rede. Então, hoje em dia tem que estar filiado na entidade regional, estadual e federal, e como é uma rede sindical, o objetivo nosso é justamente ser filiado e participar das ações, das políticas discutidas e decididas num conjunto pela FATRES para fortalecer o movimento sindical. Porque a gente sozinha, isolada, não vai para lugar nenhum (Secretária de Políticas Públicas do SINTRAF de Serrinha) ${ }^{7}$.
\end{abstract}

O depoimento da liderança do sindicato de trabalhadores rurais do município de Serrinha permite variadas possibilidades de interpretações. Considerando, no entanto, os propósitos deste trabalho, podemos destacar pelo menos dois grandes sentidos associados às noções basilares de rede e de escala.

O conteúdo expressa, em primeiro lugar, uma compreensão sobre o funcionamento do movimento sindical concebido pela entrevistada como uma rede, manifestando, por conseguinte, uma nítida intenção de participação nas redes sindicais pela importância estratégica que tal procedimento implica. Essa constatação reforça a conclusão de Scherer-Warren (1999) sobre o caráter assumido pelo conceito de rede, seja como estratégia para as ações coletivas, seja como forma de organização e de atuação dos sujeitos coletivamente organizados.

Esses argumentos nos permitem uma ousadia de ordem teórica, que consiste na defesa da acepção de que a rede pode ser considerada tanto uma categoria de análise quanto uma categoria da prática social, apropriando, assim, da ideia originalmente desenvolvida por Moore (2008) para a escala, uma vez que "o termo rede é utilizado tanto pela ciência, como conceito teórico ou metodológico, quanto por atores sociais que passaram a empregar essa noção para se referirem a determinado tipo de relação ou prática social" (SCHERER-WARREN, 1999, p. 21).

Em segundo lugar, o depoimento reflete com clare-

Entrevista concedida a Ariane Matos em 17/2/2010, pela Secretária de Políticas Sociais do Sindicato dos Trabalhadores Rurais e Agricultores Familiares de Serrinha. 
za uma visão estratégica sobre as políticas de escalas envolvidas no funcionamento do sindicalismo rural brasileiro, assim como da mutiescalaridade da organização do fenômeno sindical, indicando, finalmente, a necessidade e a importância de uma ação multiescalar para o fortalecimento da ação sindical na escala local. Essa constatação reforça o argumento de que a escala é uma categoria da prática, "(...) na medida em que os atores pensam e agem em termos escalares e as relações sociais e instituições são organizadas de acordo com preceitos escalares" (MOORE, 2008, p. 218, tradução nossa). Esse comportamento dos agentes sociais nos remete também ao que Vainer (2002, p. 25) denominou de estratégias transescalares, considerando que "qualquer projeto (estratégia) de transformação envolve, engaja e exige táticas em cada uma das escalas em que hoje se configuram os processos sociais, econômicos e políticos estratégicos".

A análise do comportamento espacial das organizações sociais sediadas no Espaço Sisaleiro da Bahia nos permite identificar como elas empreendem uma variada gama de ações que denominamos no âmbito deste trabalho de estratégias-rede, considerando a centralidade assumida pela ideia e pela prática de formação e de participação em redes. Nesse sentido, concebemos "(...) a rede como meio de ação estratégica", no sentido empregado por Marcon e Moinet (2001, p. 162), e como elemento constitutivo da natureza dessas organizações. As estratégias-rede se caracterizam pelo desenvolvimento de políticas de escala, nas quais os agentes sociais se articulam em diferentes escalas, construindo estratégias de ação multiescalares.

Marcon e Moinet (2001) questionam a existência de um modelo universal de rede, pois, como se trata de construções humanas, "são soluções sempre específicas que os homens, com recursos e capacidades disponíveis, inventaram, a fim de estruturar suas interações em e para a resolução de problemas comuns" (CROZIER e FRIEDBERG apud MARCON e MOINET, 2001, p. 130). Desse modo, elas dependem de cada campo de ação coletiva e podem se manifestar por meio de "alguns modelos mais conhecidos: associações, clubes, federações, alianças, parcerias, consórcios, grupos informais etc." (MARCON e MOINET, 2001, p. 131).

Em termos empíricos, a estratégia-rede, objeto de nossa investigação, se manifesta por meio de algumas práticas socioespaciais que expressam um comportamento escalar das organizações sociais, num movimento que implica (i) a constituição e a participação em redes regionais e nacionais de sindicalismo, cooperativismo e economia solidária; (ii) a participação em conselhos, fóruns, feiras e outras modalidades de redes de articulação política e econômica, estruturadas nas escalas regional (seguindo as delimitações dos Territórios de Identidade), estadual (escala de governo) e nacional; e (iii) o estabelecimento de parcerias com agentes situados nas mais variadas escalas espaciais.

O primeiro movimento mencionado acima consiste na estratégia de agrupamento de organizações-rede na escala local/microrregional e regional para formação de organizações-rede mais complexas que operam em escalas mais amplas. Um caso exemplar de formação de rede na escala regional pode ser atribuído ao processo de criação da Associação das Cooperativas de Apoio à Economia Familiar (ASCOOB). Essa associação de cooperativas foi fundada em 1999, "por iniciativa de 05 cooperativas de crédito rural voltados para o fortalecimento da agricultura familiar e economia solidária"8 localizadas no semiárido baiano. Trata-se, portanto, de um fenômeno organizativo do cooperativismo de crédito rural, assumindo a forma de rede, que apresenta como característica um movimento espacial ascendente que parte das experiências e iniciativas locais/microrregionais e vai compondo formas organizacionais novas, tecendo uma rede de relações de cooperação em escalas geográficas de maior amplitude.

A ASCCOB foi concebida com o objetivo de "pensar coletivamente questões comuns a todas as cooperativas, como, por exemplo, a melhor sistematização do crédito e as negociações de acesso a recursos oficiais"9. A associação de cooperativas criada em 1999 constituiu uma cooperativa central em 2008 (a ASCOOB Central), passando a oferecer seus serviços com base em quatro eixos estratégicos: (i) educação cooperativista; (ii) apoio à assistência técnica e extensão rural; (iii) apoio à gestão financeira; e (iv) microfinanças. Atualmente, a rede formada pela ASCOOB Central é integrada por 10 cooperativas $^{10}$, que dispõem de 36 agências e recobrem 88 municípios do Estado da Bahia, atendendo a mais de 45.000 cooperados. $^{11}$

Portanto, as organizações-rede não restringem sua ação a uma única escala, mas operam em múltiplas escalas. Essa estratégia é válida para os sindicatos de trabalhadores rurais e para as cooperativas de agricultores que organizam suas federações e confederações, apropriando-se das mais diversas escalas espaciais.

0 fragmento que reproduzimos a seguir sintetiza o processo de criação da Federação dos Trabalhadores e Trabalhadoras na Agricultura Familiar do Brasil (FETRAF-Brasil), evidenciando sua estrutura multiescalar, valendo-se, sobretudo, das escalas de governo para sua estruturação como organização-rede:

\footnotetext{
$\overline{8}$ Informação disponível em: <http://www.ascoobcentral.com.br/nossa-historia. php>. Acesso em: 15 set. 2012.

IInformação disponível em: <http://www.ascoob.org.br/quemsomos.php>. Acesso em: 18 mai. 2010.

${ }^{10}$ Três das cooperativas filiadas à ASCOOB estão sediadas no Espaço Sisaleiro da Bahia: a Cooperativa de Crédito Rural Ascoob Itapicuru (ASCOOB ITAPICURU), a Cooperativa de Crédito Rural Ascoob Sisal (ASCOOB SISAL), e a Cooperativa de Crédito Rural Ascoob Cooperar (ASCOOB COOPERAR). ${ }^{11}$ Informação disponível em: <http://www.ascoobcentral.com.br/nossa-historia. php>. Acesso em: 15 set. 2012.
} 
Este processo de reorganização do sindicalismo rural iniciou-se pela Região Sul, com a fundação da Federação dos Trabalhadores na Agricultura no Estado de Santa Catarina - FETRAFESC/CUT em 1997. Mas é a criação da Federação dos Trabalhadores na Agricultura Familiar - FETRAF-Sul em 2001, nos Estados de Rio Grande do Sul, Paraná e Santa Catarina, que foi dado o grande impulso a este processo. Posteriormente vieram as Federações da Agricultura Familiar - FAFs em São Paulo e Mato Grosso do Sul; e as FETRAFs na Bahia, Rio Grande do Norte, Ceará, Piauí, Pernambuco, Distrito Federal e Entorno, Minas Gerais, Maranhão, Goiás, Pará, Mato Grosso, Tocantins e Paraíba. Nos Estados de Amazonas, Rio de Janeiro, Alagoas e Amapá estão em fase de consolidação. Todas essas Federações se organizam a partir da base, incorporando e articulando SINTRAFs, STRs, Associações, Cooperativas, Assentamentos, Agroindústrias, grupos de produção de jovens e mulheres agricultoras familiares. No mês de julho de 2004, mais de $\mathbf{2 . 0 0 0}$ agricultores/ as familiares provenientes de 22 estados do País participaram em Brasília do $1^{\circ}$ Encontro Nacional Sindical da Agricultura Familiar, no qual decidiu-se por aclamação aprofundar e estender por todo o Brasil o processo de reorganização e reestruturação sindical da Agricultura Familiar através da Federação dos Trabalhadores e Trabalhadoras na Agricultura Familiar do Brasil - FETRAF-Brasil/CUT. (Disponível em: <http:// www.fetraf.org.br/site/quem_somos.php>. Acesso em: 15 set. 2012 , grifo nosso).

A descrição do processo de criação das federações sindicais mostra claramente que elas se baseiam predominantemente nas escalas de governo. A FETRAF-Brasil constitui-se numa rede nacional de sindicalismo gestada e sustentada por uma tessitura de organizações-rede em outras escalas: municipal, estadual, macrorregional (usando as grandes regiões do IBGE).

Um movimento análogo se constata na conformação das redes nacionais de cooperativismo, como no caso da Confederação Nacional de Cooperativas de Crédito do Sicoob. A SICOOB Federação é constituída pelas cooperativas centrais organizadas na escala estadual, que, por sua vez, são resultantes da articulação das cooperativas de crédito organizadas na escala local/microrregional. 0 fragmento de texto seguinte esclarece esse modo de estruturação em rede que conforma o SICOOB Federação, ocupando-se de funções estratégicas como a integração, a padronização do sistema cooperativista e a definição de políticas institucionais para toda a rede:

As cooperativas de crédito singulares fazem parte dessa grande organização social, chamada de Sistema Sicoob. São instituições financeiras resultantes da união de pessoas integrantes de segmentos econômicos específicos, que buscam a melhor maneira de atendimento às suas necessidades financeiras. (Disponível em: <http://www.sicoob.com.br/site/ conteudo/sistema_sicoob/cooperativas_singulares/>. Acesso em: 15 set. 2012)

Com o intuito de incrementar a qualidade dos serviços prestados aos associados, as cooperativas singulares do Sicoob se organizaram e constituíram as cooperativas centrais de crédito, como forma de ampliar ainda mais a capacidade de atendimento. (Disponível em:<http://www.sicoob.com.br/site/ conteudo/sistema_sicoob/cooperativas_centrais/>.
Acesso em: 15 set. 2012)

A Confederação Nacional de Cooperativas de Crédito do Sicoob - Sicoob Confederação é uma cooperativa de terceiro grau [...] constituída pelas cooperativas centrais do Sistema, com a finalidade de defender os interesses das cooperativas representadas, promovendo a padronização, supervisão e integração operacional, financeira, normativa e tecnológica. Define ainda, políticas e estratégias de comunicação e marketing, principalmente em relação à marca Sicoob. (Disponível em:<http://www.sicoob.com.br/site/ conteudo/sistema_sicoob/sicoob_confideracao/>. Acesso em: 15 set. 2012)

Os dois exemplos acima arrolados, informando os modos de estruturação de uma rede nacional de cooperativismo e de sindicalismo, mostram como organizações-rede em diferentes escalas são ativadas para compor essa estratégia-rede. A rede, organizada nacionalmente, existe (e faz sentido) na medida em que diversas organizações-rede na escala local e regional se articulam e viabilizam sua estruturação, conformando uma organização-rede multiescalar.

Considerando como pressuposto que as organizações sociais se constituem e constroem suas ações conformando estratégias-rede que se organizam e operam em diversas escalas espaciais, é possível afirmar que a escala se torna, portanto, um conteúdo fundamental da articulação dessas organizações-rede, que a acionam como recurso organizacional e espacial de luta e empoderamento. Portanto, os modos como essas organizações (e os sujeitos sociais envolvidos) acionam as escalas geográficas como componentes de suas estratégias de luta, empoderamento, afırmação e sobrevivência permitem-nos pensar como essas entidades, através de "táticas e estratégias espaciais 'têm tentado manipular a escala de modo a fortalecer suas posições de barganha" (MOORE apud BRANDÃO, 2009, p. 172) e viabilização de seus projetos sociopolíticos.

Todavia, há outras formas segundo as quais as estratégias-rede se materializam. 0 segundo movimento que as caracteriza se manifesta nos procedimentos de participação em conselhos, fóruns, feiras e outros tipos de redes de articulação política e produtiva. Nesse sentido, a rede se constitui em uma ampla estratégia de ação que coloca em conexão e em movimento uma diversificada e densa rede de organizações sociais, equivalendo ao que Scherer-Warren (2007) denominou de coletivos em rede. Isso reforça nossa hipótese de trabalho, sustentada no argumento de que a noção de rede parece constitutiva e fundadora das ações e das estratégias acionadas por variadas modalidades organizacionais da sociedade civil. 
O Quadro 1 nos oferece uma evidência contundente sobre o grau de intensidade investido pelas mais proeminentes organizações sociais do Espaço Sisaleiro da Bahia na participação nas instâncias/"espaços" de militância política (conselhos, fóruns, câmaras) e em canais de articulação econômica (feiras e redes produtivas). Uma característica inequívoca desses espaços/canais é a natureza escalar que os fundamenta, seguindo, predominantemente, as escalas institucionais de governo. Em consequência disso, os agentes sociais empreendem um comportamento espacial multiescalar, participando de conselhos e fóruns de agricultura familiar, economia solidária, cooperativismo, assistência técnica e comunicação, estruturados na escala municipal (conselhos gestores de políticas públicas), regional (que vem sendo tratada e concebida como territorial na Política Desenvolvimento Territorial Rural do Ministério do Desenvolvimento Agrário e pelas políticas púbicas no Estado da Bahia), estadual e nacional (Quadro 1).
O Quadro 1 nos permite atestar, também, que quase todas as principais organizações-rede focalizadas nesta pesquisa ocupam uma cadeira no conselho territorial (CODES Sisal), criado pela Política Nacional de Desenvolvimento Territorial Rural do Ministério do Desenvolvimento Agrário (MDA). A delimitação espacial dos territórios rurais, institucionalizados pelo funcionamento dos conselhos territoriais no âmbito do MDA, e sua utilização de modo mais incisivo pelo governo da Bahia, na formulação de políticas públicas, indicam a constituição de outra escala de planejamento governamental, assentada, no caso baiano, sobre a regionalização dos Territórios de Identidade.

QUADRO 1

PARTICIPAÇÃO DAS ORGANIZAÇÕES SOCIAIS DO TERRITÓRIO DO SISAL EM CONSELHOS, FÓRUNS, FEIRAS E OUTROS TIPOS DE REDES.

\begin{tabular}{|c|c|c|c|c|}
\hline ENTIDADE & $\begin{array}{l}\text { ESCALA } \\
\text { LOCAL }\end{array}$ & ESCALA REGIONAL (1) & ESCALA ESTADUAL (1) & ESCALA NACIONAL \\
\hline Abraço Sisal & & $\begin{array}{l}\text { - Conselho Territorial } \\
\text { (CODES Sisal) }\end{array}$ & $\begin{array}{ll}\text { - Conselho de } & \text { de } \\
\text { Comunicaçāo } & \text { do } \\
\text { Estado da Bahia; } \\
\text { - Fórum Baiano da } \\
\text { Agricultura Familiar } \\
\text { (FBAF). }\end{array}$ & \\
\hline $\begin{array}{l}\text { APAEB Valente } \\
\text { Fundaçāo } \\
\text { APAEB }\end{array}$ & $\begin{array}{l}\text { - Conselhos } \\
\text { Municipais } \\
\text { de Valente. }\end{array}$ & $\begin{array}{l}\text { - Conselho Territorial } \\
\text { (CODES Sisal) }\end{array}$ & $\begin{array}{l}\text { - Rede Parceiros da } \\
\text { Terra (REPARTE); } \\
\text { - Fórum Baiano da } \\
\text { Agricultura Familiar } \\
\text { (FBAF). }\end{array}$ & \\
\hline Arco Sertāo & & $\begin{array}{l}\text { - Conselho Territorial } \\
\text { (CODES Sisal); } \\
\text { - Conselho Territorial } \\
\text { (CODES Jacuípe); } \\
\text { - Conselho Gestor do } \\
\text { Fundor Rotativo } \\
\text { (COGEFUR). }\end{array}$ & $\begin{array}{l}\text { - Fórum Estadual de } \\
\text { Economia Solidária; } \\
\text { Câmera Técnica } \\
\text { Estadual de } \\
\text { Comercializaçāo. }\end{array}$ & $\begin{array}{l}\text { - Fórum Nacional do } \\
\text { Cooperativismo de } \\
\text { Crédito de Economia } \\
\text { Familiar e Solidária; } \\
\text { - UNICAFES. }\end{array}$ \\
\hline CEAIC (2) & $\begin{array}{l}\text { - Conselhos } \\
\text { Municipais } \\
\text { de Santaluz. }\end{array}$ & $\begin{array}{l}\text { - Conselho Territorial } \\
\text { (CODES Sisal); } \\
\text { - Conselho Gestor do } \\
\text { Fundor Rotativo } \\
\text { (COGEFUR). }\end{array}$ & $\begin{array}{l}\text { - Fórum Baiano da } \\
\text { Agricultura } \\
\text { (FBAF) }\end{array}$ & \\
\hline
\end{tabular}




\begin{tabular}{|c|c|c|}
\hline COOBENCOL (3) & $\begin{array}{l}\text { - Conselho Territorial } \\
\text { (CODES Sisal) }\end{array}$ & \\
\hline COOPERAFIS (4) & $\begin{array}{l}\text { - Conselho Territorial } \\
\text { (CODES Sisal); } \\
\text { - Rede BODEGA } \\
\text { (sediada em Paulo } \\
\text { Afonso } \\
\text { empreendimentos da } \\
\text { Caatinga). }\end{array}$ & \\
\hline FATRES(5) & $\begin{array}{l}\text { - Conselho Territorial } \\
\text { (CODES Sisal); } \\
\text { - Conselho Gestor do } \\
\text { Fundorativo } \\
\text { (COGEFUR) }\end{array}$ & $\begin{array}{l}\text { - Conselho Estadual do } \\
\text { PRONAF (Programa } \\
\text { Nacional de } \\
\text { Fortalecimento da } \\
\text { Agricultura Familiar); } \\
\text { - Rede Parceiros da } \\
\text { Terra (REPARTE); } \\
\text { Fórum Baiano da } \\
\text { Agricultura Familiar } \\
\text { (FBAF). }\end{array}$ \\
\hline
\end{tabular}

Fonte: Pesquisa de Campo, 2011-2012

Notas: (1) Estamos distinguindo uma escala estadual em função da existência de conselhos, fóruns e redes que se organizam segundo escala de governo. Por outro lado, queremos reforçar a construção de outra escala (regional) de planejamento, baseada nos Territórios de Identidade. (2) Centro de Apoio às Iniciativas Comunitárias do Semiárido da Bahia. (3) Cooperativa de Beneficiamento e Comercialização. (4) Cooperativa Regional de Artesãs Fibras do Sertão. (5) Fundação de Apoio aos TrabaIhadores Rurais e Agricultores Familiares da Região do Sisal e Semiárido da Bahia.

Elaboração: Agripino Souza Coelho Neto.

Analisando os coletivos em rede, Scherer-Warren (2007) enumerou uma variedade de experiências de formação de redes e de participação nas instâncias políticas, entre as quais comparecem algumas das manifestações mais frequentemente adotadas pelas entidades do Espaço Sisaleiro da Bahia, conforme grifo na citação abaixo, interpretando o fenômeno do seguinte modo:

\begin{abstract}
Nas esferas públicas nacionais e locais os coletivos em rede e as redes de movimentos sociais também têm desempenhado um papel relevante como atores de resistência e propositores de políticas cidadãs. No Brasil, tem-se, como exemplos significativos, redes estratégicas de denúncias (Diretas Já, Caras Pintadas, Grito dos Excluídos etc.); redes de estratégias de desobediência civil (acampamentos dos Sem-Terra e dos Sem-Teto); redes de combate à exclusão (Ação da Cidadania, Economia Solidária); redes de negociação na esfera pública (Agenda 21, Conselhos Setoriais, Orçamento Participativo). (SCHERER-WARREN, 2007, p. 42, grifo nosso)
\end{abstract}

As esferas públicas não se restringem às escalas local e nacional como mostra nossa empiria, configurando-se também em outras escalas de governo, como a estadual e a recém-conformada escala regional/"territorial" dos conselhos territoriais da política do $\mathrm{MDA}^{12}$.

A participação nessas esferas nem sempre se caracteriza como resistência, no entanto, são cada vez mais

${ }^{12}$ Vale salientar que o MDA, em um de seus documentos referenciais, define o território como uma escala intermediária entre o municipal e o estadual. Obviamente, não podemos ignorar o empobrecimento imputado ao conceito com esse emprego, que foi objeto de uma crítica que elaboramos em Coelho Neto (2013). recorrentes a motivação e o interesse despertados pela possibilidade de proposição de políticas públicas. A constituição de conselhos gestores e de fóruns de discussão/encaminhamento de demandas tem operado considerando a proposta de diálogo entre Estado e Sociedade civil, configurando o que Rancière (1996) chamou de "pós-democracia consensual". Esse preceito de funcionamento, que tem como referências a negociação entre segmentos da sociedade civil com o Estado (sustentados pela construção de consensos políticos) e a perspectiva de consecução de vantagens (com a aprovação de projetos e a obtenção de recursos públicos), ajuda a explicar a presença expressiva das organizações sociais nos "espaços de participação", cujos significados políticos e sociais discutiremos no próximo capítulo.

A organização e a participação em feiras de agricultura familiar e economia solidária consistem em uma estratégia que tem se multiplicado nesta última década. 0 conjunto de fragmentos reunidos a seguir nos permite constatar sua periodicidade, sua organização escalar, os principais agentes envolvidos e as mais frequentes atividades desenvolvidas:

Acontecerá nos dias 19, 20 e 21 de maio [de 2010], em Serrinha, a $3^{a}$ Feira da Agricultura Familiar e Reforma Agrária do Território do Sisal. Realizada pelo Movimento Social do Território com o apoio de várias entidades públicas. O CODES Sisal convida a população do Território de Sisal para participar desta Feira que trará para Serrinha diversas oficinas temáticas, 
exposições de produtos da agricultura familiar, animais e manifestações culturais. (Disponível em: <http:// www.arcosertao.org.br/vernoticia.php?idNoticia $=73>$. Acesso em: 14 mai. 2012, grifo nosso)

A $2^{\text {a }}$ Agrifam Sisal - Feira da Agricultura Familiar da Região do Sisal acontece entre 11 e 13 de novembro de 2011, em São Domingos/BA. Durante a realização da feira serão tratados assuntos referentes à crise que enfrenta o sisal, mas também ao crescimento de culturas como: produção de leite de caprinos e bovinos, criação de caprinos e produção de mel. (Disponível em: <http://agroevento.com/agenda/2-agrifam-sisal/> Acesso em: 14 mai. 2012, grifo nosso)

Stand da ARCO SERTÃO representa empreendimentos cooperativos solidários da agricultura familiar na FEBAFES 2011 - II Feira Baiana de Agricultura Familiar e Economia Solidária (Disponível em: <http://www. arcosertao.org. br/vernoticia. php?idNoticia $=104>$. Acesso em: 14 mai. 2012, grifo nosso)

A Arco Sertão marcou presença no I Seminário Nacional do Instituto Consulado da Mulher - Programa Usinas do Trabalho nos dias 05 e 07 de outubro, na cidade de Embu das Artes/SP. 0 seminário reuniu parceiros do Programa Usinas do Trabalho. (Disponível em: <http:// www. arcosertao.org. br/vernoticia. php?idNoticia $=83>$. Acesso em: 14 mai. 2012)

O Ministério do Desenvolvimento Agrário vai realizar no período de 07 a 12 de outubro [2009], no Rio de Janeiro, a sexta edição da Feira Nacional da Agricultura Familiar e Reforma Agrária. (Disponível em: <http://www.agrolink.com.br/eventos/EventoDetalhe. aspx?CodEvento=4794>. Acesso em: 14 mai. 2012)

Portanto, é possível concluir que se trata de um expediente regularmente acionado, com espacialidade e periodicidades bem definidas pelas entidades sociais representativas dos agricultores/trabalhadoras, constituindo-se em canais de articulação política e econômica, nos quais são desenvolvidas atividades mercantis e trocas de experiências e saberes, viabilizando a construção de alianças e parcerias. As notícias acima arroladas nos revelam como as feiras são organizadas com base nos mais variados recortes escalares como Território do Sisal, Região do Sisal, Estado da Bahia e Brasil.

Algumas feiras são promovidas pelo governo (em suas distintas esferas), no entanto, as organizações sociais do Espaço Sisaleiro da Bahia têm assumindo crescente protagonismo na tarefa de realização das feiras (com apoio e, às vezes, em parceria com agências governamentais), manipulando as escalas espaciais de acordo com suas conveniências e interesses. A notícia abaixo reproduzida é um caso exemplar desse expediente de reorganização escalar, na qual as entidades ampliam a escala de organização da feira e lhe conferem maior amplitude espacial e densidade organizacional e política.
Entidades de agricultores do Sertão baiano realizam de 10 a 12 deste mês de maio [de 2007] na cidade de Feira de Santana o II Ciclo da Agricultura Familiar e Economia Solidária dos Territórios do Sisal, Bacia do Jacuípe e Portal do Sertão (Feira de Santana) [...]. Segundo a assessoria do MOC, Movimento de Organização Comunitária, em 2006, o I Ciclo da Agricultura Familiar foi realizado na cidade de Serrinha e contemplava apenas o Território do Sisal, que a mudança para a cidade de Feira de Santana foi devido ao forte caráter comercial da cidade e a inclusão do Portal do Sertão no evento e que, durante os três dias, a população de Feira de Santana poderá conferir o artesanato e demais produtos originados dos territórios envolvidos que acontecem na Praça Bernadinho Bahia. (Disponível em: <http:// www.studiorural.com/?noticia=112>. Acesso em: 14 mai. 2012)

O terceiro movimento que caracteriza a estratégia-rede das organizações sociais do Território do Sisal é o estabelecimento de parcerias com os mais diferentes segmentos da sociedade sediados na escala local, regional, nacional e global. A parceria constitui-se num arranjo em que duas ou mais partes estabelecem um acordo de cooperação costurado em torno de interesses comuns. Portanto, a realização de parcerias pressupõe a ativação de conexões entre agentes sociais, preenchendo empiricamente os requisitos do que Scherer-Warren (2007) denominou de coletivos em rede, assentados na formação de alianças voltadas para a busca de apoios solidários ou para o desenvolvimento de estratégias de ação conjunta.

A despeito da existência de um contexto político-institucional mais propício para a realização de parcerias com as agências governamentais e as secretarias de governo (nos governos petistas), o maior volume de parcerias se dá entre as próprias organizações sociais, como se pode certificar no Quadro 2. Dessa primeira constatação mais geral desdobram-se outras duas mais específicas e mais relevantes para nossos propósitos de análise: (i) verifica-se maior concentração de parcerias formalizadas entre entidades situadas na escala local e regional; e (ii) as parcerias são realizadas em sua esmagadora maioria entre as entidades oriundas das organizações de agricultores/trabalhadores rurais (sindicatos de trabalhadores rurais, cooperativas de crédito e de produção, associações comunitárias rurais e as organizações-rede complexas como as centrais de associações, cooperativas e sindicatos).

Esse conjunto de constatações, sobretudo no que se refere ao volume de parcerias firmadas entre organizações sediadas nas escalas local e regional, engendrando um comportamento de reciprocidade e de cooperação, reforça nosso argumento a favor da existência de um tecido social organizado no Espaço Sisaleiro da Bahia, que se articula por meio de diferentes expedientes, dentre os quais as parcerias. 0 depoimento reproduzido a seguir 
representa um testemunho cabal do fenômeno que estamos destacando:

Hoje nós temos parcerias com a APAEB, com a Fundação APAEB, com a CEAIC, com a Arco Sertão. Com todas essas instituições que sempre dá o apoio. Apoio de mão dupla, tanto daqui pra lá, tanto de lá pra cá. A APAEB neste período de crise mesmo a gente foi também um dos que deu maior apoio para ela não cair Agora mesmo na Feira [refere-se à Feira de Agricultura Familiar e Economia Solidária prevista para 2012], a gente senta todo mundo e cada um vai assumir determinadas funções. (Presidente da FATRES) ${ }^{13}$
Entretanto, a configuração desse expediente da estratégia-rede atravessa outras escalas espaciais, como revela o Quadro 2. Essa constatação se torna mais contundente quando analisamos as parcerias estabelecidas por duas das mais tradicionais $\mathrm{e}$ expressivas entidades do Espaço Sisaleiro da Bahia (Quadro 3). Enquanto a SICOOB-COOPERE mantém um fluxo mais intenso de trocas com a escala local (mais frequentemente com rádios e associações comunitárias e com os sindicatos de trabalhadores rurais), a APAEBValente estabelece uma forte densidade de relações com a escala nacional, mas, sobretudo, com a escala global.

\begin{tabular}{|c|c|c|c|c|}
\hline ENTIDADE & ESCALA LOCAL & $\begin{array}{l}\text { ESCALA } \\
\text { REGIONAL }^{(1)}\end{array}$ & $\begin{array}{l}\text { ESCALA }^{(1)} \\
\text { ESTADUAL }^{(1)}\end{array}$ & $\begin{array}{l}\text { ESCALA } \\
\text { NACIONAL }\end{array}$ \\
\hline CEAIC & APAEB Valente. & $\begin{array}{l}\text { MOC }^{(2)} \text {, FATRES e } \\
\text { ASCOOB Itapicuru. }\end{array}$ & & CESE ${ }^{(3)}$. \\
\hline COOBENCOL & CEIAC. & $\begin{array}{l}\text { ASCOOB Itapicuru e } \\
\text { Arco Sertão. }\end{array}$ & & \\
\hline COOPERAFIS & $\begin{array}{l}\text { Fundação } \\
\text { APAEB. }\end{array}$ & SICOOB Coopere. & $\begin{array}{l}\text { SEBRAI Bahia; } \\
\text { SEDES }^{(4)} \text {. }\end{array}$ & SESI. \\
\hline FATRES & $\begin{array}{l}\text { APAEB Valente; } \\
\text { Fundação APAEB } \\
\text { e CEIAC. }\end{array}$ & $\begin{array}{l}\text { Arco Sertão e CODES } \\
\text { Sisal; Abraço Sisal; } \\
\text { SICOOB Coopere. }\end{array}$ & $\begin{array}{l}\text { CAR }^{(5)} ; \quad \text { EBDA }^{(6)} ; \\
\text { FETRAF } \\
- \text { BAA }^{(7)}\end{array}$ & $\begin{array}{l}\text { CONAB }^{(8)} \\
\text { UNICAFES }^{(9)}\end{array}$ \\
\hline Arco Sertão & $\begin{array}{l}\text { Prefeitura } \\
\text { Municipal } \\
\text { Serrinha; } \\
\text { (10). }\end{array}$ & $\begin{array}{l}\text { MOC; Abraço Sisal; } \\
\text { CODES } \\
\text { CODES Sisal; } \\
\text { MMTR }^{(11)} \text {; FATRES. }\end{array}$ & $\begin{array}{l}\text { SUDIC }^{(12)} ; \\
\text { SEAGRI } \\
\text { FETRAF -BA. }\end{array}$ & $\begin{array}{l}\text { MDA; } \\
\text { UNICAFES. }\end{array}$ \\
\hline Abraço Sisal & STRs. & MOC; Arco Sertão. & SECULT -BA ${ }^{(14)}$ & $\begin{array}{l}\text { DESOP } \\
\text { Brasil( }^{(15)}\end{array}$ \\
\hline
\end{tabular}

Fonte: Pesquisa de Campo, 2011-2012.

Notas: (1) Optamos por distinguir a Escala Regional (Espaço Sisaleiro da Bahia) da Escala Estadual (escala de governo) em decorrência de duas motivações: (i) para destacar as parcerias que se configuram no âmbito do Espaço Sisaleiro; (ii) para enquadrar as parcerias estabelecidas com instituições do Governo da Bahia ou organizações que se organizam (e operam) segundo as escalas de governo. (2) Movimento de Organização Comunitária. (3) Coordenadoria Ecumênica de Serviço. (4) Secretaria de Desenvolvimento Social e Combate à Pobreza. (5) Companhia de Desenvolvimento e Ação Regional. (6) Empresa Baiana de Desenvolvimento Agrícola S.A. (7) Federação dos Trabalhadores na Agricultura Familiar do Estado da Bahia. (8) Companhia Nacional de Abastecimento. (9) União Nacional das Cooperativas de Agricultura Familiar e Economia Solidária. (10) Sindicatos de Trabalhadores Rurais. (11) Movimento de Mulheres Trabalhadoras Rurais. (12) Superintendência de Desenvolvimento Industrial e Comercial. (13) Secretaria Estadual de Agricultura, Irrigação e Reforma Agrária. (14) Secretaria de Cultura do Estado da Bahia. (15) Instituto Belgo-brasileiro de Cooperação para o Desenvolvimento Social.

Elaboração: Agripino Souza Coelho Neto 
A rede de cooperação e parceria tecida pela APAEBValente envolve uma diversidade de agentes sociais (ministérios e secretarias de governo, agências governamentais, bancos nacionais de desenvolvimento, fundações privadas internacionais, organizações não governamentais nacionais e internacionais, organizações religiosas, associações comunitárias, cooperativas de crédito), e apresenta um comportamento multiescalar (Quadro 3).
O Quadro 3 revela a impressionante rede de relações que a entidade mantém com a escala global, configurando numa rede de cooperação religiosa nucleada na Europa Ocidental [Misereor ${ }^{14}$, Pão para o Mundo (Brot Für Die Welt) ${ }^{15}$, Manos Unidas ${ }^{16}$ e Cordaid ${ }^{17}$ ] e com diversos apoios financeiros oriundos de fundações norte-americanas e europeias. Os recursos financeiros recebidos pela APAEB-Valente se destinam, preferencialmente: (i) ao pagamento de salários e deslocamentos da assistência técnica que a entidade fornece aos agricultores; (ii) à realização de cursos e treinamentos, alguns voltados para a convivência com o semiárido; (iii) ao pagamento de monitores, aquisição de material didático e fornecimento de alimentação para os alunos da Escola Família Agrícola (EFA) mantida pela associação; e (iv) ao custeio de parte do projeto de comunicação comunitária, por rádio e televisão (APAEB, 2004).

\footnotetext{
14"Misereor é a obra episcopal da Igreja Católica da Alemanha para a cooperação ao desenvolvimento. Desde há mais de 50 anos, Misereor está comprometida com a luta contra a pobreza na África, Ásia e América Latina" (Disponível em: <//www. misereor.org/pt/about-us.html>. Acesso em: 10 set. 2012).

${ }^{15} \mathrm{~A}$ "Pão para o Mundo" (Brot Für Die Welt) é uma agência de cooperação vinculada às igrejas evangélicas regionais da Alemanha (Disponível em: <http://www.brot-fuer-die-welt.de/home.html>. Acesso em: 10 set. 2012).

16"Manos Unidas es la Asociación de la Iglesia Católica en España para la ayuda promoción y desarrollo del Tercer Mundo. Es, a su vez, una organización no gubernamental para el desarrollo (ONGD), de voluntarios, católica y seglar" (Disponível em: <http://www.manosunidas.org/organizacion>. Acesso em: 10 set. 2012)

${ }^{17} \mathrm{~A}$ Cordaid é uma organização da Igreja Católica de ajuda e desenvolvimento sediada na Holanda, com uma rede de cerca de mil organizações parceiras em 36 países na África, Ásia e América Latina (Disponível em: <http://www.cordaid.nl/nl/ (12997)--.html>. Acesso em: 10 set. 2012)
} 


\begin{tabular}{|c|c|c|}
\hline ESCALAS & APAEB VALENTE & SICOOB COOPERE \\
\hline LOCAL & $\begin{array}{l}\text { - Igreja Católica (Valente); } \\
\text { - Fórum da Cidadania (Valente); } \\
\text { - Associações Comunitárias (de } \\
\text { Valente e do Espaço Sisaleiro da } \\
\text { Bahia). }\end{array}$ & $\begin{array}{l}\text { - APAEB Valente; } \\
\text { - Rádios Comunitárias do Território } \\
\text { do Sisal e Bacia do Jacuípe; } \\
\text { Associações Comunitárias Rurais; } \\
\text { - STRs (Capim Grosso, Conceição } \\
\text { do Coité, Gavião, Itiúba, Monte } \\
\text { Santo, Nova Fátima, Queimadas, } \\
\text { Quixabeira, Retirolândia, Santaluz e } \\
\text { Valente); } \\
\text { - Prefeituras Municipais (Capim } \\
\text { Grosso, Conceição do Coité, Gavião, } \\
\text { Nova Fátima, Quixabeira, } \\
\text { Retirolândia e Valente); } \\
\text { - União das Associações } \\
\text { Comunitárias de Nova Fátima } \\
\text { (UNANF). }\end{array}$ \\
\hline REGIONAL & $\begin{array}{l}\text { ASCOOB Feira de Santana; MOC; } \\
\text { IRPAA (Juazeiro) }^{(1)}\end{array}$ & COOPERAFIS E FATRES. \\
\hline ESTADUAL & $\begin{array}{l}\text { SECTI }^{(2)} ; \text { SEAGRI; }^{\text {CAR; }} \\
\text { DESENBAHIA }^{(3) ;} \text { REFAISA }{ }^{(4)} \text {; } \\
\text { AECOFABA }{ }^{(5) ;} \text { SEBRAI -BA; SUDIC; } \\
\text { UEFS. }\end{array}$ & \\
\hline NACIONAL & $\begin{array}{l}\text { BNDES (6); Caritas Brasileira; Fundação } \\
\text { Getúlio Vargas; EMBRAPA }{ }^{(7) ;} \text { MDA; } \\
\text { INFRAERO }{ }^{(8)} ; \text { FASE }^{(9)} \text {; ASHOKA Brasil; } \\
\text { CERIS }{ }^{(10)} \text {; CONAB. }\end{array}$ & DISOP Brasil; UNICAFES. \\
\hline GLOBAL & $\begin{array}{l}\text { - Inter American Foundation e } \\
\text { Fundação Kellogg (EUA); } \\
\text { - ONGs M isereor, Pão para o Mundo } \\
\text { e Leteinamerika Zentrum E. V.; e } \\
\text { Fundação Heinrich Boll (Alemanha); } \\
\text { - Fundação DOEN e ONG CORDAID } \\
\text { (Holanda); } \\
\text { - ONG Manos Unidas (Espanha); } \\
\text { - Fondazione II Canalli (Itália); } \\
\text { - Kreditibank e ONGs SIMFR, SOS - } \\
\text { PG e DISOP (Bél gica); } \\
\text { - Schwab Foundation (Suíça). }\end{array}$ & BID $^{(11)}$; DISOP Bélgica. \\
\hline
\end{tabular}

Fonte: Pesquisa de Campo, 2011-2012; Relatório Anual de Atividades da APAEB dos anos de 2000 a 2010; Relatório Anual de Atividades do SICOOB COOPERE dos anos de 2008 a 2010

Notas: (1) Instituto Regional da Pequena Agropecuária Apropriada. (2) Secretaria de Ciência, Tecnologia e Inovação do Estado da Bahia. (3) Agência de Fomento do Estado da Bahia S/A. (4) Rede das Escolas Famílias Agrícolas Integradas do Semiárido. (5) Associação das Escolas das Comunidades e Famílias Agrícolas da Bahia. (6) Banco Nacional de Desenvolvimento Econômico e Social. (7) Empresa Brasileira de Pesquisa Agropecuária. (8) Empresa Brasileira de Infraestrutura Aeroportuária. (9) Federação de Órgãos para Assistência Social e Educacional. (10) Centro de Estatística Religiosa e Investigações Sociais. (11) Banco Interamericano de Desenvolvimento. Elaboração: Agripino Souza Coelho Neto. 


\section{Considerações finais}

Em conformidade com o entendimento de Moore (2008), a escala não é somente um artificio teórico para leitura da realidade, que no nosso caso equivale dizer que se trata do instrumental para interpretação do comportamento espacial das redes de organizações sociais, mas se constitui em aporte para a ação dos grupos sociais, que se apropriam delas para o desenvolvimento de suas estratégias de luta e empoderamento.

Em resumo, podemos constatar que as diversas modalidades que compõem e conformam as estratégiasrede expressam as políticas de escala, que são adotadas pelas organizações sociais, caracterizando-se por sua natureza multiescalar. As organizações sociais do Espaço Sisaleiro da Bahia acionam as diferentes escalas, especialmente as escalas de governo, para subsidiar a intervenção no mundo.

Vale destacar que há um movimento espacial ascendentenocomportamento das redes deorganizações sociais (cooperativas de agricultores, associações comunitárias rurais e sindicatos de trabalhadores rurais), pois as organizações-rede estruturadas em escalas de maior amplitude (como a escala nacional e estadual) se sustentam e se apoiam na existência de organizaçõesrede nas escalas local e microrregional.

Embora essas ideias tenham sido desenvolvidas com base nas experiências empíricas do Espaço Sisaleiro da Bahia, consideramos que a formação de estratégias-rede e a construção de políticas de escala podem ser adotadas para leitura da espacialidade das organizações sociais em outros contextos tempo-espaço pela capacidade de generalização que elas apresentam. 
ACSELRAD, H. (2002) Território e Poder: a política das escalas. In: FICHER, T. (Org.). Gestão do desenvolvimento e poderes locais: marcos teóricos e avaliação. Salvador: Casa da Qualidade.

APAEB. (2001) Relatório Anual 2000. Valente: APAEB, 60 p.

. (2002) Relatório Anual 2001. Valente: APAEB, 68 p.

(2004) Relatório Anual 2003. Valente: APAEB, 74 p.

(2005) Relatório Anual 2004. Valente: APAEB, 75 p.

(2006) Relatório Anual 2005. Valente: APAEB, 25 p.

(2007) Relatório Anual 2006. Valente: APAEB, 16 p.

(2010) Relatório Anual 2009. Valente: APAEB, 30 p.

(2010) Exemplo de luta e realizações. Valente: APAEB, 5 p.

(2011) Relatório Anual 2010. Valente: APAEB, 35 p.

ARCO SERTÃO. (s/d) Catálogo de Produtos. Valente: Arco Sertão, 22 p.

BRANDÃO, C. (2009) Desenvolvimento, territórios e escalas espaciais: levar na devida conta as contribuições da economia política e da geografia crítica para construir a abordagem interdisciplinar. In: RIBEIRO, M. T. F.; MILANI, C. R. S. (orgs.). Compreendendo a complexidade socioespacial contemporânea: o território como categoria de diálogo interdisciplinar. Salvador: EDUFBA, p. 151-186.

(2010) Producción social del ambiente construido y sus escalas espaciales: notas para una teoría acerca de las acciones y decisiones de sujetos concretos. In: FERNÁNDEZ, V. R.; BRANDÃO, C. Escalas y políticas del desarrollo regional: desafíos para América Latina. Buenos Aires/Madrid: Miño y Dávila, p. 241-272.

CASTRO, I. E. (1995) O problema da escala. In: CASTRO, I. E. de (org.). Geografia: conceitos e temas. Rio de Janeiro: Bertrand Brasil.

COELHO NETO, A. S. (2013) A Política de Desenvolvimento Territorial Rural no Brasil e a banalização do conceito de território. Revista Brasileira de Desenvolvimento Regional, v. 1, p. 107-124.

DALLABRIDA, V. R. (2010) La escala en los procesos de gestión del desarrollo: revisión teórica, análisis de experiencias y aportes a la investigación. In: FERNÁNDEZ, V. R.; BRANDÃO, C. Escalas y políticas del desarrollo regional: desafíos para América Latina. Buenos Aires/Madrid: Miño y Dávila, p. 185-216.

GONZÁLEZ, S. (2010) Las narrativas escalares da globalización: neoliberalismo y ciudades competitivas. In: FERNÁNDEZ, V. R.; BRANDÃO, C. Escalas y políticas del desarrollo regional: desafíos para América Latina. Buenos Aires/Madrid: Miño y Dávila, p. 123-149.

HARVEY, D. (2000) Espaços da esperança. São Paulo: Loyola.

JONES, K. (1998) Scale as epistemology. Political Geography, n. 17, p. 25-28.

KURTZ, H. (2003) Scale frames and counter-scale frames: constructing the problem of environmental injustice. Political Geography, n. 22, p. 887-916.

MARCON, C.; MOINET, N. (2001) Estratégia-rede: ensaio de estratégia. Caxias do Sul: EDUCS.

MARSTON, S. (2000) The social construction of scale. Progress in Human Geography, v. 24, n. 2, p. 219-242, apr.

MOORE, A. (2008) Rethinking scale as a geographical category: from analysis to practice. Progress in Human Geography, v. 32, n. 2, p. 203-225, apr.

PAASI, A. (2004) Place and region: looking through the prism of scale. Progress in Human Geography, v. 28, n. 4, p. 536-546, out.

RANCIÈRE, J. (1996) O desentendimento. São Paulo: Editora 34.

SCHERER-WARREN, I. (1999) Cidadania sem fronteiras: ações coletivas na era da globalização. São Paulo: Hucitec.

(2007) Redes sociais: trajetórias e fronteiras. In: DIAS, L. C.; SILVEIRA, R. L. L. (orgs.). Redes, Sociedade e Ter-

ritório. 2. ed. Santa Cruz do Sul: EdUNISC. 
SICOOB-COOPERE. (2004) Relatório Anual 2003. Valente: SICOOB-COOPERE, 58 p.

. (2009) Relatório Anual 2008. Valente: SICOOB-COOPERE, 27 p.

(2010) Relatório Anual 2009. Valente: SICOOB-COOPERE, 43 p.

(2011a) Relatório Anual 2010. Valente: SICOOB-COOPERE, 47 p.

(2011b) Boletim Informativo. Valente, n. 27, abril, 4 p.

(2011c) Boletim Informativo. Valente, n. 30, novembro, 4 p.

SINTRAF/COITÉ. (2012) Boletim Informativo. Conceição do Coité, ano 02, edição 02, janeiro.

SMITH, N. (1993) Homeless/global: scaling places. In: BIRD, J.; CURTIS, B.; PUTNAM, T.; ROBERTSON, G.; TICKNER, L. (eds.). Mapping the futures. London: Routledge, p. 87-119.

(2000) Scale. In: JOHNSTON, R. J.; GREGORY, D.; PRATT, G.; WATTS, M. (eds.). The dictionary of human geography. Malden-MA: Blackwell, p. 724-27.

SWYNGEDOUW, E. (1997) Excluding the other: the production of scale and scaled politics. In: LEE, R.; WILLS, J. (eds.). Geographies of economies. London: Arnold, p. 167-76.

(2010) Globalización o glocalización? Redes, territórios y reescalamiento. In: FERNÁNDEZ, V. R.; BRANDÃO, C. Escalas y políticas del desarrollo regional: desafíos para América Latina. Buenos Aires/Madrid: Miño y Dávila, p. 47-75.

VAINER, C. (2002) As escalas do poder e o poder das escalas: o que pode o poder local? Cadernos do IPPUR, Rio de Janeiro, ano XVI, n. 1, p. 13-32, jan-jul. 